\title{
Drug policy: we need brave politicians and open minds
}

\author{
Fiona Godlee editor in chief, The BMJ
}

When it comes to policies for tackling drug misuse, we need an evidence based approach. These are not my sentiments, though I share them; these are the views of the leaders of all the UK political parties as expressed in recent government reports and a debate in parliament that gained cross party support.

So we at The BMJ asked ourselves: what would an evidence based drug policy look like? And we invited Nicola Singleton and John Strang to give us their answer (doi:10.1136/bmj. g7493). It is perhaps worth stating at this point that my own view chimes with Margaret McCartney's in her column this week (doi:10.1136/bmj.g7273). "Drug dependence is a problem that needs medical care and attention-not criminal sanctions," she writes. "We need a government grown up enough to put policy where the evidence is."

Singleton and Strang don't quite say this, although they come close. They acknowledge a growing consensus that viewing drug problems as a public health rather than a criminal justice concern tends to be more effective. The negative effects of criminalising and imprisoning drug misusers are well documented, they say, and countries that have taken less prohibitionist approaches have not reported huge increases in harms. They also say that if the UK government is serious about having evidence based policies it must show the political will to accept the evidence even if this is at odds with its prior beliefs. But their main conclusion is that there is no single simple solution. Drug misuse is multifaceted, and "what works" is rarely clear cut and often contested. Different interventions will need to be properly trialled and evaluated, and policies will need to adapt over time and to suit different circumstances. They want to see "evidence infused policy" in an environment in which politicians, policy makers, and practitioners are open to evidence of failure as well as success. Above all, they say that we need honest and open minded engagement from the public and the media, the implication being that this is not what we have at the moment.

What about how the public and the media engage with the results of medical research? As Ben Goldacre writes in an editorial this week, for anyone with medical training the mainstream media's coverage of science can be an uncomfortable read (doi:10.1136/ bmj.g7465). But is this the fault of the journalists or the researchers? Petroc Sumner and colleagues looked at press releases from universities and conclude that most of the blame lies with the researchers-or more specifically with the press releases they allow to go out in their name (doi:10.1136/bmj. g7015). Many contain exaggerated advice and claims of causal effect or unjustified inferences, for humans, from animal studies. Interestingly, they found no evidence that hyping the results led to more coverage.

True to their findings, Sumner and colleagues are scrupulous in stating the limitations of their own study. They make it clear that, because it's a retrospective correlational analysis, it can't show a causal association between hyped press releases and hyped news stories. And I'm pleased to note that our own press release for this study makes no exaggerated claims. "Most exaggeration in health news is already present in academic press releases," it says, and "the scientific community has the ability to improve this situation." Enough said.

Cite this as: BMJ 2014;349:97603

๑ B BMJ Publishing Group Ltd 2014 